\title{
HISTOLOGIC AND PHYSIOLOGIC EVALUATION OF SKELETONIZED INTERNAL THORACIC ARTERY HARVESTING WITH AN ULTRASONIC SCALPEL
}

Tetsuya Higami, MD Ayako Maruo, MD

Teruo Yamashita, MD

Tsutomu Shida, MD

Kyoichi Ogawa, MD
Objectives: The safety and reliability of a method of skeletonized internal thoracic artery harvesting with an ultrasonic scalpel (Harmonic Scalpel; Ethicon Endo-Surgery, CVG, Cincinnati, Ohio) were evaluated.

Methods: The mural branches of the internal thoracic artery were cut by means of 3 methods, differentiated by distance from the site of application of the Harmonic Scalpel blade to the internal thoracic artery. A total of 15 branches were cut from the internal thoracic artery at $(0 \mathrm{~mm})$ the origin (group I) or at $1 \mathrm{~mm}$ (group II) or $2 \mathrm{~mm}$ (group III) distal to the origin. Tissue preparations were examined for successful vessel closure and severity of tissue damage. The length of stump (L) and the length of tissue damage from the stump (D) were determined by a computer image analysis system, and pressure testing was performed to evaluate the physical strength of vessel closure.

Results: In group I, 8 of the 15 branches exhibited discontinuity of the vascular wall structure, probably because of insufficient sealing of the divided section, and 12 of the 15 branches exhibited tissue denaturation on the internal thoracic artery wall adjacent to areas of origin, which was probably caused by the heat transferred from the branches during the process of coagulation. In groups II and III, continuity of wall structure of stumps suggestive of stable closure of branches was confirmed. The lengths of tissue damage from the stump (D) were $0.96,0.58$, and $0.63 \mathrm{~mm}$ in groups I, II, and III, respectively, and the lengths of intact area $(\mathrm{L}-\mathrm{D})$ in the corresponding groups were $-0.78,0.61$, and $1.51 \mathrm{~mm}$. The negative figure in group I indicates the presence of tissue damage in the internal thoracic artery itself. By contrast, in groups II and III the internal thoracic arteries were intact, with a safety margin of greater than $0.5 \mathrm{~mm}$. On physiologic evaluation of vessel closure, 2 of the $24(8.3 \%)$ branches burst under a pressure lower than 350 $\mathrm{mm} \mathrm{Hg}$ because of insufficient vessel coagulation, but the remaining 22 branches $(91.7 \%$ ) remained intact under pressures up to $350 \mathrm{~mm} \mathrm{Hg}$.

Conclusion: The internal thoracic artery skeletonization method with an ultrasonic scalpel (Harmonic Scalpel: output level 2) appears to be a safe and reliable method of skeletonized internal thoracic artery harvesting when branches are sectioned at least $1 \mathrm{~mm}$ distal to their origin at a sufficiently slow speed. (J Thorac Cardiovasc Surg 2000;120:1142-7)
From the Division of Cardiovascular Surgery, Hyogo Brain and Heart Center, Himeji, Japan.

Received for publication Feb 23, 2000; revisions requested April 10, 2000; revisions received May 19, 2000; accepted for publication July 18, 2000.

Address for reprints: Tetsuya Higami, MD, Division of Cardiovascular Surgery, Hyogo Brain and Heart Center, 520 Saisho-ko, Himeji 670-0981, Japan (E-mail: thigami@hbhc.hiabcd.go.jp).

Copyright (C) 2000 by The American Association for Thoracic Surgery.

0022-5223/2000 $\$ 12.00+0 \quad \mathbf{1 2 / 1 / 1 1 0 1 8 9}$

doi:10/1067/mtc. 2000.110189
U se of an internal thoracic artery (ITA) graft to the $\bigcup$ left anterior descending coronary artery is associated with superior patency rates and longer survival than use of saphenous vein grafts. ${ }^{1-4}$ This arterial conduit can be used as a pedicled, free graft or skeletonized vessel. It is clear that the ITA graft obtained as a pedicle functions well in myocardial revascularization procedures. A skeletonization technique of ITA dissection has significant potential advantages. ${ }^{5-7}$

We have developed a new technique for harvesting skeletonized ITAs safely and simply by using an ultra- 

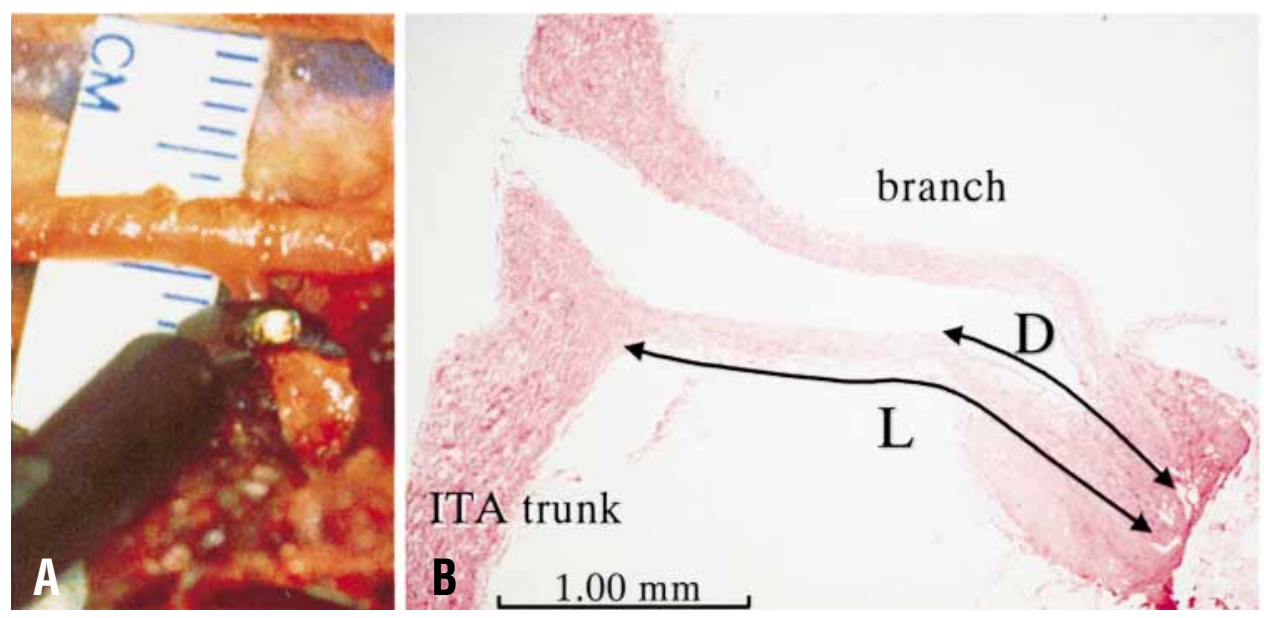

Fig 1. A, An ITA mural branch cut and coagulated with the Harmonic Scalpel. B, Method used for measuring the branch length $(L)$ and the length of the damaged intima $(D)$ on a photomicrograph by a computer image analysis system.

sonic scalpel. ${ }^{8}$ This new method has enabled us to obtain longer ITAs with minimal invasiveness and with results similar to or better than with conventional methods of pedicle isolation. In addition, it has substantially expanded the area of possible coverage with an ITA graft. Here we report the results of histologic and physiologic evaluation of the safety and precision of our new method of skeletonized ITA harvesting with an ultrasonic scalpel in experimental animals.

\section{Material and methods}

Six randomly selected pigs weighing 37 to $43 \mathrm{~kg}$ (average, $39.5 \mathrm{~kg}$ ) were used in this study. Their care and use complied with the "Principles of Laboratory Animal Care" and the "Guide for the Care and Use of Laboratory Animals" published by National Institutes of Health (NIH publication 8523, revised 1985).

All subjects were administered proper anesthesia, which was induced with 5 to $10 \mathrm{~mL}$ of $4 \%$ thiamylal intravenously and then maintained with a combination of $0.5 \%$ to $1.0 \%$ halothane and a mixture of nitrous oxide and oxygen in a 2:1 ratio through an endotracheal tube connected to a closed circuit respirator. The entire length of the bilateral ITAs was approached via median sternotomy and was carefully skeletonized with the aid of an ultrasonic scalpel (Harmonic Scalpel; Ethicon Endo-Surgery, CVG, Cincinnati, Ohio) from its origin to the bifurcation of the musculophrenic and superior epigastric arteries. All ITA mural branches were divided. The Harmonic Scalpel was operated at level 2 with a dissecting hook blade (DH105), the top of which (blunt side, $1 \mathrm{~mm}$ wide) was applied to the target branch and activated to contact the mural branch until the branch is divided (Fig 1, A). Nine of 12 ITAs were used for the histologic evaluation and 3 ITAs for the physiologic examination.

Histologic evaluation. The ITA mural branches were cut by means of 1 of the following 3 methods, differentiated by distance from the site of application of the blade of the Harmonic Scalpel to the ITA: 15 branches of 3 ITAs (group I) were cut from the ITA immediately at the origin $(0 \mathrm{~mm})$; 15 branches of another 3 ITAs (group II) were cut at $1 \mathrm{~mm}$; and 15 branches of another 3 ITAs (group III) were cut at 2 $\mathrm{mm}$ distal to the origin.

After fixation with $10 \%$ buffered formalin solution, all segmental tissue blocks including divided mural branches were taken from all ITAs. Cross sections were then prepared from these tissue blocks and stained with hematoxylin-eosin for general histologic study. Photomicrographs were taken of all cross sections. These photomicrographs were used to evaluate the completeness of vessel sealing and the severity of tissue damage of the branches and ITAs. The range of tissue damage to each stump was evaluated quantitatively by a computer image analysis system (Macintosh; Apple Computer, Inc, Cupertino, Calif) on the basis of the length of each residual branch (L, the length between the edge of each stump and its origin, measured along the inner surface) and the length of tissue damage ( $\mathrm{D}$, the length from the edge of each stump to the boundary between damaged and normal tissues, measured along the inner surface) (Fig 1, B).

Physiologic evaluation. To evaluate the physical strength of vessel sealing, we conducted pressure testing on ITAs, the branches of which were sectioned at $1 \mathrm{~mm}$ distal to the origin. A total of 24 branches obtained from 3 ITAs were evaluated.

An 18-gauge cannula was inserted into the proximal end of the ITA and a ligature was placed around the cannula. The cannula was connected to both a syringe and a digital manometer (Yokogawa Electric Co, Ltd, Tokyo, Japan). The arterial segment, distal manometer, syringe, and connection tubes were filled with air and sealed off to form a closed system. A vascular bulldog clamp was placed across the ITA immediately distal to the nearest branch so that the individual branch could be tested by gradually increasing pressure within the lumen. By slowly pushing the syringe's piston, the artery's intraluminal pressure was increased until the occlud- 


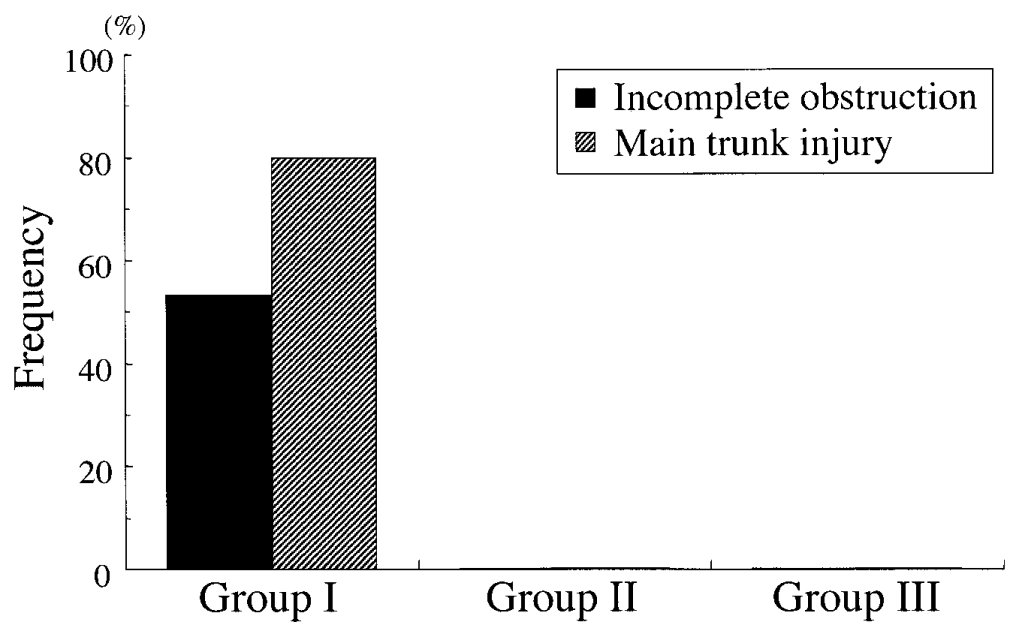

Fig 2. Frequency of incomplete obstruction of the branch and ITA trunk injury adjacent to the branch when using the Harmonic Scalpel.

ed vessel burst or pressure had increased to $350 \mathrm{~mm} \mathrm{Hg}$. The pressure curve was recorded with the manometer. The peak of the curve was considered the vessel's resistance to pressure. After that branch had been tested, a small clip was placed across it and the bulldog clamp was moved distally on the ITA just beyond the second branch, which was then tested in a similar fashion. These procedures were repeated to evaluate all branches individually.

\section{Results}

Histologic evaluation. In group I, 8 of the 15 branches evaluated exhibited discontinuity of vascular wall structure, possibly resulting from insufficient sealing of the divided section. Examination of these 8 branches showed that they were filled with hyalinized denatured tissue and/or clots. For 12 of the 15 branches, vacuolation and nuclear deformation, probably because of heating during coagulation of the branch, were noted in the wall of the ITA adjacent to the origin (Fig 2). In groups II and III, continuity of the vessel wall structure was confirmed and successful sealing of the branches appeared to be present, although there were findings of tissue degeneration in the branches, including introversion of the intima of stumps (as if they had been squeezed from the outer surface) and vacuolation of cells in the vessel wall located about $0.6 \mathrm{~mm}$ proximal to the dissected end. In groups II and III, no abnormalities were observed in the vessel wall around the origin between the ITA and the branches evaluated (Fig 3).

The lengths of tissue damage from the stump edge (D) were $0.96 \pm 0.48 \mathrm{~mm}$ (mean \pm standard deviation), $0.58 \pm 0.18 \mathrm{~mm}$, and $0.63 \pm 0.27 \mathrm{~mm}$ for groups I, II, and III, respectively. The mean differences between the length of branch (L) and D, that is, the length of intact branch to the ITA, were $-0.78,0.61$, and $1.51 \mathrm{~mm}$ in groups I, II, and III, respectively (Table I). The negative value in group I reflects the fact that the ITAs themselves had tissue damage. By contrast, the ITAs in groups II and III were free of tissue damage with a safety margin of $0.5 \mathrm{~mm}$ or more.

Physiologic evaluation. Physiologic evaluation was performed for a total of 24 branches. Two of the 24 branches $(8.3 \%$ ) burst under a pressure of $350 \mathrm{~mm} \mathrm{Hg}$; 1 branch $0.3 \mathrm{~mm}$ in diameter burst at $210 \mathrm{~mm} \mathrm{Hg}$, and 1 branch $0.5 \mathrm{~mm}$ in diameter burst at $260 \mathrm{~mm} \mathrm{Hg}$. The duration of cutting/coagulation for these 2 branches was shorter than for the other branches, suggesting that coagulation for these 2 branches had been performed inappropriately. The other 22 branches $(91.7 \%)$ resisted up to $350 \mathrm{~mm} \mathrm{Hg}$ of pressure. The time required to cut and coagulate a vessel by using the ultrasonic scalpel correlated with the outer diameter of the vessel ( $r=0.64, P=.014$ ); vessels 0.3 to $0.6 \mathrm{~mm}$ in diameter (mean, $0.48 \pm 0.11 \mathrm{~mm}$ ) required 2 to 3 seconds (mean, $2.8 \pm 0.5$ seconds), whereas those 0.7 to $1.2 \mathrm{~mm}$ in diameter (mean, $0.98 \pm 0.20 \mathrm{~mm}$ ) required 3 to $4 \mathrm{sec}$ onds (mean, $3.4 \pm 0.45$ seconds) (Fig 4).

\section{Discussion}

In 1998 we developed a new technique of ITA skeletonization with an ultrasonic scalpel. ${ }^{8}$ This method has enabled us to obtain longer ITAs with results similar to or better than those of conventional pedicle-obtaining methods. In this study we evaluated the safety and reliability of our skeletonized ITA harvesting method by observing the histopathologic effect of this technique on dissected ITAs and by testing the physical strength of branch closure. 


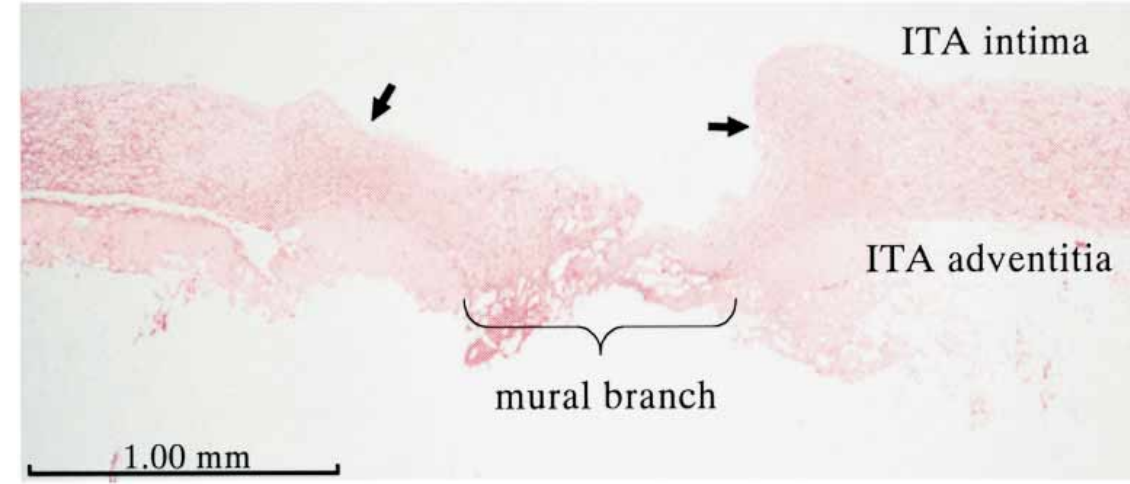

A
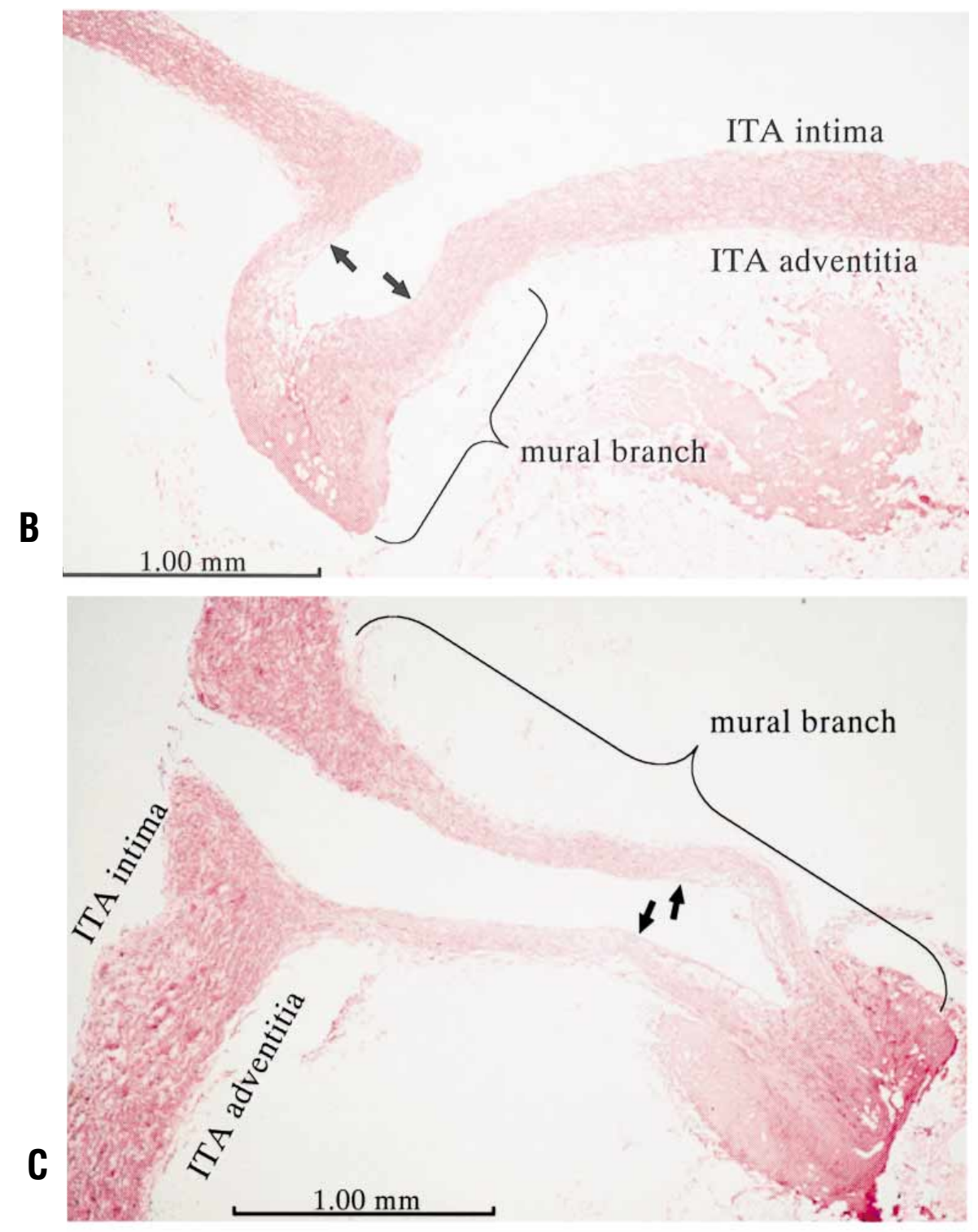

Fig 3. Representative illustrations from each group. A, The branch was incompletely obstructed with hyalinized denatured tissue and clots, and ITA trunk damage was recognized adjacent to the branch in group I. Arrows indicate the border between damaged ITA wall and normal wall. B, Group II. C, Group III. Both B and $\mathbf{C}$ show completely obstructed branch stumps and no injury to the ITA trunk wall. 


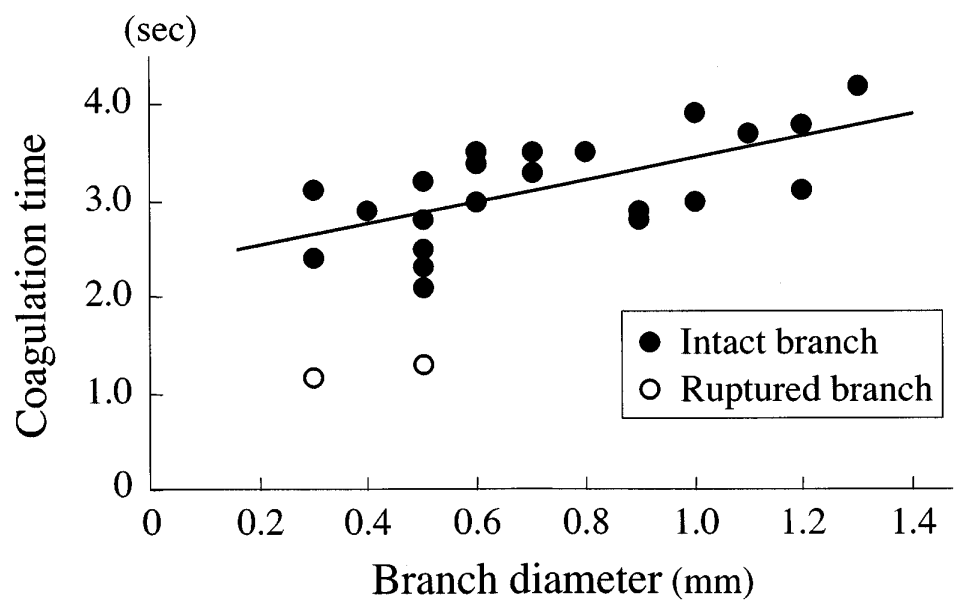

Fig 4. Correlation between branch diameter and cutting coagulation time. Intact branch: Branches that remained intact on pressure testing up to $350 \mathrm{~mm} \mathrm{Hg}$. Ruptured branch: Branches that burst at pressure less than $350 \mathrm{~mm} \mathrm{Hg}$.

Table I. Branch intimal damage and total lengths

\begin{tabular}{lccc}
\hline Group & $I(n=15)$ & $I I(n=15)$ & $I I I(n=15)$ \\
\hline L, length of branch (mm) & $0.18 \pm 0.24$ & $1.19 \pm 0.23$ & $2.14 \pm 0.39$ \\
D, length of damaged intima (mm) & $0.96 \pm 0.48$ & $0.58 \pm 0.18$ & $0.63 \pm 0.27$ \\
L-D (mm) & $-0.78 \pm 0.39$ & $0.61 \pm 0.14$ & $1.51 \pm 0.25$
\end{tabular}

Values are mean \pm standard deviation.

The ultrasonically activated scalpel (Harmonic Scalpel) uses ultrasonic energy to denature tissue protein into a sticky coagulum that seals blood vessels and bleeding tissues. Two cutting mechanisms are included in the Harmonic Scalpel that are unlike those of electrosurgery or laser surgery. ${ }^{9-11}$ The scalpel's primary mechanism for cutting is longitudinal vibration of the blade tip at 55,500 times/second over an excursion of 5 to $10 \mu \mathrm{m}$. Mechanical cutting enables the scalpel to incise high-protein-density and collagen-rich tissues such as muscle, peritoneum, and fibrous connective tissue. The protein coagulum is formed as the mechanical energy from the blade couples with the tissue protein. The mechanical energy developed is sufficient to break the hydrogen bonds that give the protein its tertiary structure. Protein disorganization and loss of biologic activity (denaturation) result in a protein coagulum that is capable of sealing vessels up to $5 \mathrm{~mm}$ in diameter without tissue desiccation or charring. This is in contrast to cutting with electrosurgery or lasers, which creates extremely high temperatures that vaporize tissues to excise them. A second cutting mechanism is cavitational fragmentation that disrupts low-density tissues such as fat and parenchyma and causes tissue planes to separate ahead of the blade tip. Cavitational tissue plane dissection facilitates dissection between planes of tissue and helps protect adjacent vital structures.

The most important procedure in ITA skeletonization with the Harmonic Scalpel is the cutting of branches. Although fat tissue adjacent to the ITA can be readily removed, without any damage to the ITA itself, via cavitational fragmentation by gently applying the blade tip to the fat tissue (as if brushing away the fat tissue with the blade tip), the branches should be cut and the edges should be coagulated while avoiding thermal damage to the ITA. Fortunately, the Harmonic Scalpel, unlike electric knives, appears to deliver ultrasonic energy mainly along the direction of the force applied to the blade, ${ }^{12}$ and it also appears that the degree of lateral energy transfer is quite small. ${ }^{11,13}$ In a study using porcine liver, stomach, and skin, Amaral and Chrostek ${ }^{14}$ reported that the depth of coagulation with the Harmonic Scalpel increased linearly with the amount of time during which power and pressure were constant, and that the depth of coagulation was $1 \mathrm{~mm}$ when energy was applied for 5 seconds. They also reported that the lateral spread of coagulation from the Harmonic Scalpel was much less than the depth of penetration $(0.5 \mathrm{~mm}$ after the 5 -second coagulation period). Kadesky and colleagues ${ }^{15}$ reported that the lateral 
energy dispersion of the Harmonic Scalpel may be less than that of cautery on the basis of histologic evaluation of tissues dissected with an ultrasonically activated scalpel in comparison with electrocautery. In a clinical study, Ohtsuka, ${ }^{16}$ Wolf, ${ }^{17}$ and their coworkers described that thoracoscopic harvest of the ITA with the Harmonic Scalpel minimized thermal damage of the ITA. To achieve this, they cut the branches by coagulating them with the blunt side of the blade and divided them with the hook side to avoid lateral thermal damage. Their method, however, is a pedicled harvest technique, which is different from our skeletonized technique. In our technique, completion of coagulation of the branch by using the blunt side of the blade results in natural division because branches of the ITA are also skeletonized without any surrounding tissues. Hence, the branch is coagulated and divided completely without turning the blade (using only the blunt side). In the present study on skeletonization, branch cutting was performed with only the blunt side of the blade. Limited lateral spread of coagulation was observed in our study; the diameter of the branches tested ranged between 0.3 and $1.2 \mathrm{~mm}$, and the width of tissue damage at the stump edge noted after cutting and sufficient coagulation of the branches (operated at level 2) ranged between $0.41 \mathrm{~mm}$ and $0.72 \mathrm{~mm}$ (mean, $0.60 \mathrm{~mm}$ ). The length of lateral spread of coagulation was about half the depth of coagulation. The size of ITA branches in human beings, about 0.3 to $1.5 \mathrm{~mm}$ in diameter, suggests that the human ITA can be skeletonized with sufficient safety and reliability if each branch is cut $1 \mathrm{~mm}$ distal to its origin. However, it is essential to position the blade perpendicular to the branch and to apply a stable force to the blade.

Branches 0.3 to $1.2 \mathrm{~mm}$ in diameter (mean, $0.73 \mathrm{~mm}$ ) were completely occluded by applying the scalpel for 3 to 4 seconds (mean, 3.1 seconds). A $0.3-\mathrm{mm}$ branch and a $0.5-\mathrm{mm}$ branch burst at pressures of $210 \mathrm{~mm} \mathrm{Hg}$ and $260 \mathrm{~mm} \mathrm{Hg}$, respectively, in pressure testing but had been cut and coagulated for only 1.5 seconds. The disruption of the vessel appeared to have been the result of insufficient time of scalpel application to fully coagulate the cut branch. However, considering the low incidence of bursting ( 2 of the 24 branches tested) and the relatively high pressures at the time of burst (210 $\mathrm{mm} \mathrm{Hg}$ and $260 \mathrm{~mm} \mathrm{Hg}$ ), the quality of vessel closure appeared to be acceptable for clinical use. In our experience, when the blade is applied perpendicularly to the target branch for 2 to 3 seconds and 3 to 4 seconds in 0.3 - to $0.8-\mathrm{mm}$ and 0.8 - to $1.2-\mathrm{mm}$ branches, respectively, protein coagulation is sufficient to ensure stable branch closure.
The results of the present study confirm the reliability and safety of the ultrasonic scalpel to skeletonize the ITA for coronary artery bypass grafting. The ultrasonic scalpel permits effective skeletonization of the ITA without causing thermal injury to adjacent structures.

\section{REFERENCES}

1. Grondin CM, Campeau L, Lesperance J, Enjalbert M, Bourassa MG. Comparison of late changes in internal mammary artery and saphenous vein grafts in two consecutive series of patients 10 years after operation. Circulation 1984;70(Suppl):I-208-12.

2. Singh RN, Sosa JA, Green GE. Long-term fate of the internal mammary artery and saphenous vein grafts. J Thorac Cardiovasc Surg 1983;86:359-63.

3. Okies JE, Page US, Bigelow JC, Krause AH, Salomon NW. The left internal mammary artery: the graft of choice. Circulation 1984;70(Suppl):I-213-21.

4. Loop FD, Lytle BW, Cosgrove DM, et al. Influence of the internal-mammary-artery graft on 10-year survival and other cardiac events. N Engl J Med 1986;314:1-6.

5. Cunningham JM, Gharavi MA, Fardin R, Meek RA. Considerations in the skeletonization technique of internal thoracic artery dissection. Ann Thorac Surg 1992;54:947-50.

6. Calafiore AM, Vitolla G, Iaco AL, et al. Bilateral internal mammary artery grafting: midterm results of pedicled versus skeletonized conduits. Ann Thorac Surg 1999;67:1637-42.

7. Cohen AJ, Lockman J, Lorberboym M, et al. Assessment of sternal vascularity with single photon emission computed tomography after harvesting of the internal thoracic artery. $\mathrm{J}$ Thorac Cardiovasc Surg 1999;118:496-502.

8. Higami T, Kozawa S, Asada T, Shida T, Ogawa K. Skeletonization and harvest of the internal thoracic artery with an ultrasonic scalpel. Ann Thorac Surg 2000;70:307-8.

9. Amaral JF. Laparoscopic application of an ultrasonically activated scalpel. Gastrointest Endosc Clin North Am 1993;3:381-92.

10. Amaral JF. Experimental development of an ultrasonically activated scalpel for laparoscopic use. Surg Laparosc Endosc 1994;4:92-9.

11. McCarus SD. Physiologic mechanism of the ultrasonically activated scalpel. J Am Assoc Gynecol Laparosc 1996;3:601-8.

12. Hambley R, Hebda PA, Abell E, et al. Wound healing of skin incisions produced by ultrasonically vibrating knife, scalpel, electrosurgery, and carbon dioxide laser. J Dermatol Surg Oncol 1988;14:1213-7.

13. Meltzer RC, Hoenig DM, Chrostek CA, et al. Porcine seromyotomies using an ultrasonically activated scalpel [abstract]. Surg Endosc 1994;8:253.

14. Amaral JF, Chrostek C. Depth of thermal injury: ultrasonically activated scalpel vs electrosurgery [abstract]. Surg Endosc 1995;9:226.

15. Kadesky KM, Schopf B, Magee JF, Blair GK. Proximity injury by the ultrasonically activated scalpel during dissection. J Pediatr Surg 1997;32:878-9.

16. Ohtsuka T, Wolf RK, Hiratzka LF, Wurnig P, Flege JB Jr. Thoracoscopic internal mammary artery harvest for MICABG using the Harmonic Scalpel. Ann Thorac Surg 1997;63:S107-9.

17. Wolf RK, Ohtsuka T, Flege JB Jr. Early results of thoracoscopic internal mammary artery harvest using an ultrasonic scalpel. Eur J Cardiothorac Surg 1998;141:S54-7. 